\title{
Influence of copper salts on gonococci
}

\author{
GUNNAR JOHANNISSON AND ANITA KARAMUSTAFA \\ Outpatient Clinic for Venereal Diseases, Sociala Huset, \\ AND \\ JOHN-ERIK BRORSON \\ Institute of Medical Microbiology, The Department of Clinical Bacteriology, University of Gothenburg, \\ Gothenburg, Sweden
}

\begin{abstract}
Summary
No difference in the incidence of gonorrhoea was observed at a venereal disease clinic between women using a copper-coil intrauterine device (IUD) and women using oral contraceptives. Experiments in vitro demonstrated that copper sulphate has a deleterious effect on Neisseria gonorrhoeae, but the presence of serum protects the gonococci from the toxic effect of copper ions.
\end{abstract}

\section{Introduction}

Copper ions have been found to exert deleterious effects on Neisseria gonorrhoeae in vitro (Fiscina, Oster, Oster, and Swanson, 1973). Cohen and Thomas (1974) described three women with copperbound intrauterine contraceptive devices who had been exposed to gonococci without having contracted the infection. They suggested that the inhibitory effect of copper ions on gonococci might also play an important role in vivo.

The aim of the present study was to investigate the suggestion that copper-bound intrauterine devices offer protection against gonorrhoea.

\section{Material and methods}

\section{Study group}

In the 3 months February to April, 1975, 392 women attended the Outpatient Clinic for Venereal Diseases, Sociala Huset, Gothenburg, Sweden. At the first visit, the patients were questioned about their reason for attending the VD Clinic, about contraceptives, and about drugs, especially antibiotics taken during the preceding 2 months. Each patient was examined three times at weekly intervals before she was considered free from gonorrhoea.

A diagnosis of gonorrhoea was made if either a smear or culture was positive for gonococci. Smears taken from the urethra, cervix, and rectum were considered positive if there was a collection of intracellular diplococci stained with methylene blue. Specimens for culture were taken from the urethra, cervix, rectum, and tonsils, and trans-

Received for publication July 4, 1975 ported in a modified Stuart's medium (Möller, 1966) to the laboratory where they were processed within 5 hours after sampling. In this series all diagnoses made by positive smears were confirmed by positive cultures.

Studies on the influence of $\mathrm{CuSO}_{4}$ on gonococci in vitro Three recently isolated strains of gonococci were exposed to various concentrations of copper sulphate. The $\mathrm{CuSO}_{4}$ was dissolved in physiological saline alone and also in a mixture of 50 per cent. physiological saline and 50 per cent. normal human serum heated to $56^{\circ} \mathrm{C}$. for $30 \mathrm{~min}$. The following concentrations of $\mathrm{CuSO}_{4}$ were used: $10^{-5} \mathrm{M}, 10^{-6} \mathrm{M}$, and $10^{-7} \mathrm{M}$.

Sampling was performed at regular intervals to determine the number of colony forming units.

\section{Results}

Oral contraceptives were used by 67 of the women and 27 ( 40 per cent.) of these were found to have gonorrhoea. Cervical cultures were positive in 26 of these 27 patients. A copper-coil intrauterine device was used by 47 of the women and nineteen ( 40 per cent.) of these were found to have gonorrhoea. Cervical cultures were positive in seventeen of these nineteen patients.

Further analysis showed that 28 of the 67 women using oral contraceptives had had intercourse with men who were known to have gonorrhoea. These women had been referred to the clinic either by the Public Health Officer or by their sexual partner. Of these 28 women, 21 ( 75 per cent.) were found to have contracted gonorrhoea.

Correspondingly, twelve of the 47 women using the copper-bound device had been referred to the VD clinic after having had intercourse with a man known to have gonorrhoea. Of these twelve patients, ten ( 83 per cent.) were found to have gonorrhoea.

The studies in vitro with gonococci exposed to copper sulphate demonstrated that gonococci are sensitive to the action of this compound when it is dissolved in physiological saline (Figure). However, the addition of serum markedly diminished the toxic effect of copper sulphate against gonococci; e.g., in the presence of serum, $10^{-5} \mathrm{M}$ copper sulphate 
$\longrightarrow$ physiological saline

...-... 50 per cent. physiological saline +50 per cent. normal human serum

$\square 10^{-5} \mathrm{M} \mathrm{CuSO}_{4}$ in physiological saline

$\longrightarrow 10^{-6} \mathrm{M} \mathrm{CuSO}_{4}$ in physiological saline

$--\Delta-10^{-5} \mathrm{M} \mathrm{CuSO}_{4}$ in 50 per cent. physiological saline +50 per cent. normal human serum

$--10^{-6} \mathrm{M} \mathrm{CuSO}_{4}$ in 50 per cent. physiological saline +50 per cent. normal human serum

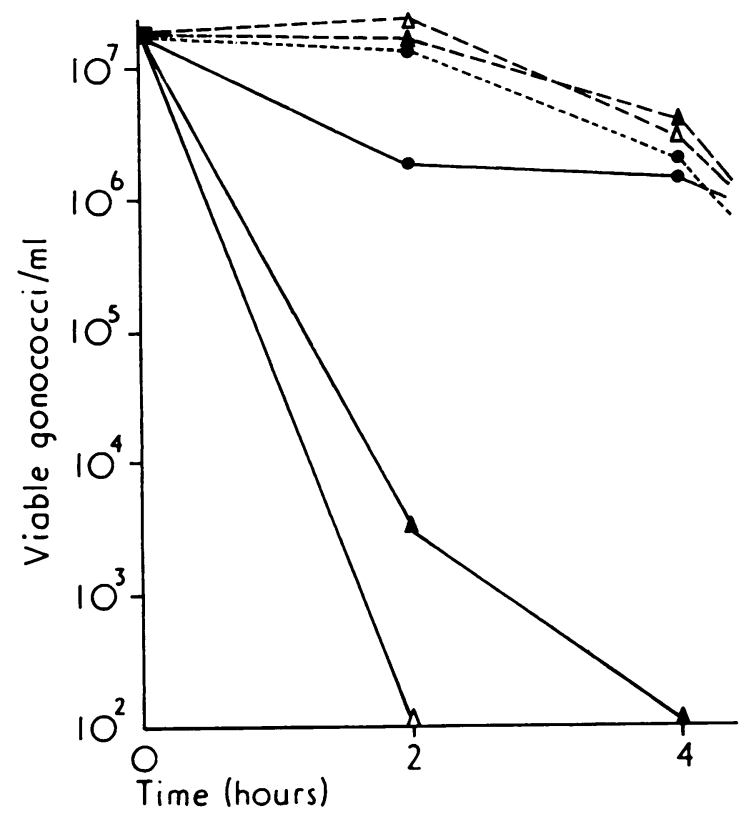

FIGURE 18-hrs-old gonococci grown on solid medium were harvested and suspended in physiological saline, and in a mixture of 50 per cent. physiological saline and 50 per cent normal human serum heated to $56^{\circ} \mathrm{C}$ for $30 \mathrm{~min}$. These systems contained different amounts of copper sulphate. Viable counts were determined on a modified Thayer-Martin medium at regular intervals

caused a reduction in the number of viable bacteria approximating to that caused by physiological saline alone, whereas the same concentration of copper sulphate dissolved in physiological saline exhibited a pronounced killing effect. The strains displayed a somewhat different sensitivity to copper dissolved in physiological saline, but the addition of serum invariably resulted in a pronounced reduction of the toxic effect.

\section{Discussion}

Copper sulphate is toxic to gonococci in certain concentrations (Fiscina and others, 1973). Further, copper ions are toxic to sperms (Odeblad 1974a). The copper concentration in cervical mucus was calculated by Fiscina and others (1973) to be at least $5 \cdot 10^{-5} \mathrm{M}$.

Hagenfeldt (1972) determined the copper concentration of cervical mucus to be higher during the proliferative phase than during the secretory phase after insertion of a $\mathrm{Cu} \mathrm{T}$ device. Odeblad (1974b) showed that the copper concentration in cervical mucus is about $10^{-6} \mathrm{M}$ in the upper part of the cervix. However, the concentration in the parts close to the external os is significantly lower than this. In cervical sinuses the concentartion of copper is very low or absent (Odeblad, 1975).

Copper ions bound to organic ligand systems, for example alanin and histidin, are less toxic to sperms than non-organic copper salts (Odeblad, 1974a). The present results indicate that the presence of organic material such as serum protects gonococci from the toxic effect of copper ions. It seems plausible to assume that organic material present in cervical mucus might protect gonococci from the toxic effect of copper. If this assumption is valid, it offers an explanation of the fact that neither Spellacy, Hiser, and Birk (1974) nor we could demonstrate any protective effect of a copper-coil IUD against gonorrhoea.

\section{References}

Cohen, L., and Thomas, G. (1974) Brit. f. vener. Dis., 50, 364

Fiscina, B., Oster, G. K., Oster, G., and Swanson, J. (1973) Amer. F. Obstet. Gynec., 116, 86

Hagenfeldt, K. (1972) Contraception, 6, 37

MöLlER, A. J. R. (1966) Thesis. Akademiförlaget, Göteborg, Sweden

ODEBLAD, E. (1974a) Report to WHO, August 5, 1974

- (1974b) Report to WHO, August 20, 1974

- (1975) Personal communication

SPEllacy, W. N., HISER, B. J., and BIRK, S. A. (1974) Fertility and Sterility, 25, 772 